\title{
TRADUCCIÓN Y CIRCULACIÓN DE LAS OBRAS DE HOFFMANN EN MÉXICO (1840-1910)
}

\author{
TRANSLATION AND CIRCULATION OF \\ HOFFMANN'S WORKS IN MEXICO (1840-1910)
}

\section{Sergio Armando HERNÁNDEZ ROURA ${ }^{1}$ \\ UNAM (México) \\ chaquirasr@yahoo.com}

Resumen: A partir de las traducciones, artículos, anuncios, notas y menciones dedicados a E. T. A. Hoffmann aparecidos en la prensa mexicana se presenta la reconstrucción del proceso de traducción y circulación de la obra del autor alemán en México. En este aspecto del fenómeno de recepción es posible apreciar el cambio de horizonte que tuvo lugar en la sociedad mexicana tanto con respecto a la obra del autor analizado como también en cuanto a la circulación de obras alemanas durante el siglo XIX y los primeros años del XX.

Palabras clave: Recepción, Hoffmann, México, circulación, traducción.

Abstract: Based on the translations, articles, announcements, notes and mentions dedicated to E. T. A. Hoffmann appeared in the Mexican press, the reconstruction of the process of translation and circulation of the work of the German author in Mexico is presented. In this aspect of the phenomenon of reception it is possible to appreciate the change of horizon that took place in Mexican society about the work of the analyzed author as well as in terms of the circulation of German works during the 19th century and the first years of the 20th.

Keywords: Reception, Hoffmann, Mexico, circulation, translation.

\footnotetext{
${ }^{1}$ Becario del Programa de Becas Posdoctorales en la UNAM, Instituto de Investigaciones Bibliográficas. Asesorado por el Dr. Vicente Quirarte Castañeda.
} 
$\mathrm{P}$ ara el estudio del destino de Hoffmann fuera de Alemania es importante considerar que su propagación a lo largo de Europa fue posterior a su muerte, ocurrida en 1822. Aunque su obra fue publicada entre 1815 y 1821 y él gozó de renombre en vida (Bravo Villasante, 1992: 116; Safranski, 2009: 199-200), a partir de ese momento comenzó el rápido proceso de difusión que lo llevaría a estimular las mentes de los escritores que lo sucedieron, comenzando en Francia por autores como Honoré de Balzac, George Sand, Prosper Merimée, Alexandre Dumas y Theophile Gautier por mencionar algunos (Breuillarc, 1906, 1907; Castex, 1951; Teichmann, 1961). A este proceso se añadió España a partir de 1831, gracias a la circulación de traducciones provenientes del francés; país en el que su huella, estudiada por Roas (2002), se hizo presente en las obras de Pedro de Madrazo, José Zorrilla, Antonio Ros de Olano, Gustavo Adolfo Bécquer, Rosalía de Castro y Benito Pérez Galdós.

Para entender la recepción que tuvo la obra de este autor en México es preciso considerar la situación de la circulación de obras alemanas previa a su difusión y sus transformaciones, de esta manera se podrá apreciar el fenómeno de cambio de horizonte ${ }^{2}$ que tuvo lugar con respecto a la circulación y publicación de obras alemanas y, en particular, con la obra de Hoffmann en el contexto mexicano.

\section{La literatura alemana en México}

Si bien la circulación de textos en la Nueva España estuvo determinada por restricciones de carácter oficial, lo cierto es que en el siglo XVIII no sólo llegaron obras de procedencia alemana, principalmente de tema religioso, a las que se sumaron poco a poco textos de carácter científico y médico, sino que, como señala O. de Bopp (1961, 23-37), la población novohispana tuvo conocimiento de las traducciones que se hacían en España, procedentes del francés. Las primeras noticias sobre literatura alemana llegaron como resúmenes que daban cuenta de la producción de esa época y de traducciones tanto de obras poéticas como científicas en los periódicos ${ }^{3}$.

\footnotetext{
${ }^{2}$ El fenómeno estudiado es parte de un proceso más amplio y complejo en el que están involucradas la circulación de obras en francés y la traducción al castellano, hecha en España o en México, la adaptación, la crítica y la asimilación por parte de los autores mexicanos. El estudio pormenorizado de cada uno de estos aspectos, del que este trabajo forma parte, permite dar cuenta de la adopción de un género o modo literario, el fantástico, considerado ajeno a la sensibilidad mexicana dentro de un proceso dinámico, apartado de la imagen monolítica con la que se tiende a contemplar las obras del periodo: "La obra literaria no es un objeto inexistente para sí que ofrezca a cada observador el mismo aspecto en cualquier momento. No es ningún monumento que revele monológicamente su esencia intemporal. Es más bien como una partitura adaptada a la resonancia siempre renovada de la lectura, que redime el texto de la materia de las palabras y lo trae a la existencia actual" (Jauss, 2000: 161). Así pues, los aspectos estudiados permiten dar cuenta del "cambio de horizonte", es decir, su normalización, cuando su presencia se da por hecho y forma parte del bagaje cultural del lector promedio y, sobre todo, la "actualización" (Jauss, 2000, p. 162) o asimilación de la obra del Hoffmann por los escritores mexicanos.

${ }^{3}$ De acuerdo con O. de Bopp (1961: 58), el primer artículo referido a la literatura alemana que se leyó en México apareció en 1789. Proveniente del Diario Encyclopédico y reimpreso por el Espíritu de los mejores diarios que se publican en Europa, núm. 177 (pp. 1118-1122) con el título "Discurso sobre los progresos de la literatura en el norte de Alemania,
} 
Como se ha dicho, con la finalidad de mantener el "aislamiento espiritual de la Nueva España" (O. de Bopp, 1961: 31) en lo que respecta a la difusión de ideas ilustradas, se practicó la censura y se elaboraron índices hacia la década de 1790, medidas que se relajaron en 1815, al calor de la guerra de Independencia, y permitieron, como consecuencia, la difusión de obras provenientes de otras latitudes, como las de Chateaubriand, Buffon, Grandison, Richardson, Smith o Milton (O. de Bopp, 1961: 37), y, con ellas, sobre todo la introducción de nuevas ideas.

En los primeros años de vida independiente la circulación de las obras alemanas, se vio afectada por la prohibición a la que estuvo sometida; si bien existía un interés creciente por las novedades que venían de ahí como parte de la recepción de otras literaturas, el desconocimiento prevalecía. Esta situación se fue mitigando poco a poco con la consolidación del circuito del libro en la etapa independiente, es decir, en este caso la formación de traductores, editores y un público lector interesado en esas obras.

Al principio del siglo XIX, pocas personas en México habrán tenido una idea verdadera de la literatura alemana. Y lo que se está perfilando en la prensa es un cuadro curioso, desfigurado como un espejismo, singular, incompleto y tardío. Será por la lejanía, o por la dificultad del alemán, el caso es que muchos de los nombres están deformados, a veces irreconocibles; los títulos de las obras tienen muchos errores de imprenta, y frecuentemente no hay ni autor ni traductor para identificarlos. Hay artículos llenos de inexactitudes, con juicios erróneos, escritos sin conocimientos, que enaltecen a algunos grandes personajes, y a su lado se encuentran nombres de segundo rango, sin relación con su importancia verdadera, y obras sin importancia que aparecen como representativas. Pero a pesar de todos los defectos es indudable que el interés por la literatura alemana es tan grande como el que existe por todas las demás lenguas de Europa (O. de Bopp, 1961: 60).

Es claro que esto se debe en buena medida al recelo que los productos culturales llegados de Alemania generaban en los sectores conservadores de la población, ya que se le seguía viendo como cuna del protestantismo y, por lo mismo, como "paladín de la libertad de pensamiento para los liberales" (O. de Bopp, 1961: 61), una visión que desapareció muy lentamente. Sobre este aspecto, visto por Rukser (1977: 12), como la "confrontación de dos mundos", es importante puntualizar que la iglesia siguió velando por este aspecto hasta la década de 1830, momento en que cambiaron las leyes sobre la prohibición de libros, durante la presidencia de Antonio López de Santa Anna y la vicepresidencia de Valentín Gómez Farías. Esta medida marcó la primera etapa de reformas de carácter liberal que pretendían limitar la intervención de la Iglesia en asuntos públicos (Staples, 1997: 112113).

O. de Bopp (1961: 65) señala que en El Iris (1826) aparecieron las primeras noticias de los poetas alemanes Klopstock, Gleim, Lessing y Goethe. De ellos, este último parece haber sido el primer autor alemán traducido en México ${ }^{4}$. La aparición de sus obras, difundidas principalmente en traducciones

\footnotetext{
leído en la Academia de las Ciencias de Berlín por el abad Denina”. Dicha publicación, una de las más exitosas de finales del reinado de Carlos III y comienzos de Carlos IV, contribuyó a la difusión del pensamiento ilustrado.

${ }^{4}$ Entre las primeras traducciones de obras en alemán se encuentra "La novia de Corinto" ("Die Braut von Korinth", 1797), con la firma de José María Heredia y sin el nombre de Goethe en Miscelánea (1829) y repetido en El Amigo de la juventud (1835) (O. de Bopp, 1961: 80). Se publicó también en La Época Ilustrada (1883) bajo el título "La desposada de Corinto", y nuevamente en El Cronista de México (1882), El Correo de la Señoras (1890-1). Fausto, una de sus obras más célebres, apareció en el periódico católico La Cruz en 1855 (O. de Bopp, 1961: 87).
} 
francesas y españolas (O. de Bopp, 1961: 84), no estuvo exenta de polémicas al respecto de su valor, pertinencia, o moralidad (O. de Bopp, 1961: 80-85)

Estas consideraciones permiten entender algunas características de la circulación de obras literarias en esa época. Un ejemplo ilustrativo sobre el proceso de traducción de textos alemanes en México es el de Friedrich Schiller, que circuló en el país a partir de la década de 1830 (O. de Bopp, 1961: 99). Su caso muestra la ruta de introducción más habitual, las complejidades e imperfecciones que caracterizaron los procesos de edición de sus obras en aquellos años:

Pero todo eso no quiere decir que Schiller haya sido conocido, sino de un número muy reducido de personas cultas. Lo primero que México conoce de él viene a través de Francia; traducciones que naturalmente tienen que sufrir por la doble versión, y una serie de juicios tanto inteligentes como también falsos y desfigurados. Lo que llega es una idea francesa de Schiller, el poeta del "Sturm und Drag", una idea altamente diferente del Schiller clásico. Para México, la fuente para el conocimiento de Schiller no es, como en Europa, tanto Madame Stäel y su libro — sus obras parecen haber llegado a México únicamente después de1830, en francés; la versión de su juicio sobre Schiller aparece hasta 1873 en la prensa mexicana, -la mayoría de las críticas y traducciones de su poesía en español tiene por fuente a Xavier Marmier, germanista francés (O. de Bopp, 1961: 100-101).

La circulación y traducción de obras en lengua alemana respondió a un proceso selectivo, en el que jugó un papel fundamental la mediación de los traductores así como la legitimación de las obras en el ámbito francés, hegemonía que marcó el rumbo de la literatura europea durante casi todo el siglo XIX. En este sentido, puede decirse que las grandes obras del romanticismo alemán no llegaron a México directamente, como en el caso de Francia, sino mediatizadas por la lengua francesa y en la mayor parte de los casos por las traducciones españolas. Como se menciona en la cita anterior, en este proceso tuvo un lugar destacado el germanista y traductor francés Xavier Marmier (1808-1892), uno de los principales difusores de la obra de autores alemanes en Francia. Como se verá más adelante, su trabajo también es relevante para el proceso que se siguió en España y México (O de Bopp, 1961: 141143).

El caso de Jean Paul Richter, que comenzó a publicarse en 1844, es otro ejemplo que vale la pena considerar. El escritor Luis Martínez de Castro, uno de sus más destacados traductores, dejó un testimonio sobre el contexto de recepción en su preámbulo a "Sueño terrorífico" de Richter publicada en el Liceo Mexicano. Tomo I, 1844 (pp. 395-397):

Aunque la lengua alemana, sin disputa, la más rica de cuantas se hablan hoy en Europa, no haya sido absolutamente cultivada, entre nosotros, no por eso no son desconocidas las producciones de algunos de los más distinguidos ingenios alemanes. No puede negarse, sin embargo, que el conocimiento que de ellos se tiene es generalmente imperfecto y superficial, porque sobre ser fundado en traducciones francesas, no todas de grande mérito a la verdad, el número de éstas es bien reducido, puesto que se limita a ciertas obras entresacadas del inmenso catálogo de autores que ha producido y produce uno de los pueblos más fecundos de Europa. Es igualmente cierto, por extraordinario que parezca, que los traductores de Francia, a pesar de su actividad y diligencia, no han conseguido todavía trasladar a su lengua todos aquellos escritos inmortales que el orbe literaria mira, y con razón, como otros tantos timbres de gloria que han ganado las diferentes naciones de Alemania (Martínez de Castro, 2003: 139).

\footnotetext{
${ }^{5}$ Algunos de estos aspectos son abordados en Rukser (1977). Sin embargo, es importante mencionar que aunque su estudio pretende abarcar la recepción de la obra de Goethe en Hispanoamérica, sitúa el fenómeno en México ya en el siglo XX, en particular en la obra de Alfonso Reyes, con Heredia como antecedente.
} 
Como se aprecia, Martínez de Castro también subraya el papel de Francia en la labor de traducción, imperfecta en no pocas ocasiones y falta de variedad en lo que respecta a las obras alemanas difundidas de este lado del Atlántico. Ante tal situación fundamenta la aproximación directa a ellas como un medio indispensable para alcanzar un conocimiento profundo de esa cultura. A este respecto el autor que gozó de mayor suerte fue Heinrich Heine, que contó con traducciones directas a partir de la década de 1830 (O. de Bopp, 1961: 126):

La obra de Heine vino únicamente al principio y en casos aislados por vía de Francia; es notable que más bien llega directamente a través de España. También en México, las traducciones directas del alemán son las más frecuentes, e indican con los conocimientos del idioma cierto interés por la literatura alemana. Pero también la marcada preferencia por la lírica juvenil de Heine, la más accesible, es significativa. Hay pocos casos de su obra crítica y de la prosa de su madurez, que no se conocen bien en México hasta nuestro siglo. No hay que olvidar sin embargo, las múltiples traducciones francesas que aquí circulan (O. de Bopp, 1961: 126).

Aunque podría objetarse que se trata de una recepción parcial de su obra, no dejan de ser encomiables los esfuerzos por brindar al público traducciones directas.

En cuanto a la aparición de textos críticos dedicados a estos autores, la situación fue muy parecida. Los juicios emitidos, en un principio eco de la crítica europea, sufrirán un proceso de autonomización de la mano de la formación de un público afín a las obras alemanas o especializado en ellas. Noticias de los autores mencionados y de otros aparecieron publicados en El Recreo de las Familias (1838), Instructor de Londres (1840-VII), el Museo de las Familias (Barcelona, 1840-I y 1841), El Siglo XIX (1843) y la Revista Científica y Literaria de México (1845) (O. de Bopp, 1961: 65-68). En las primeras miradas de conjunto "hay sólo voces muy contadas del propio México sobre la literatura alemana, casi todos los artículos provienen de España o de Francia, y son traducciones de revistas literarias francesas". A partir de la década de 1840 la situación comenzó a cambiar y "las voces críticas mexicanas ya se mezclan en el juicio sobre el cuadro literario alemán; y empiezan a abundar los más variados artículos sobre diferentes aspectos de la literatura alemana, sobre la literatura en general o sobre poetas individuales" (O. de Bopp, 1961: 68). No obstante esta notable transformación, aún en esa década era común la presencia de erratas que tenían su explicación en el desconocimiento de la lengua, situación que dejó de ser una constante hacia las últimas décadas del siglo XIX (O. de Bopp, 1961: 54). Como testimonia Manuel Payno, no era habitual leer en alemán en 1849 (O. de Bopp, 1961: 41).

De entre los textos generales que se refieren a las obras literarias ${ }^{6}$, el más destacado es Estudio de la literatura alemana de Oloardo Hassey (México: Impr. de José M. Lara, 1852), catedrático del Colegio Nacional de Minería, obra considerada como la primera historia de la literatura alemana hecha en México (O. de Bopp, 1961: 70). Fiel a su compromiso con la difusión de esa lengua y la creación de materiales didácticos, en el tomo II (México: Impr. de José M. Lara, 1854), el autor incluyó algunos fragmentos de obras de autores alemanes en lengua original a los que añade algunas traducciones. A los autores modernos dedica las siguientes líneas:

\footnotetext{
${ }^{6}$ Una descripción de algunos de ellos puede encontrarse en O. de Bopp (1961: 128-139).
} 


\begin{abstract}
Sólo mencionaremos los nombres de los escritores más conocidos entre los modernos, de los cuales algunos han recibido el epíteto de "la joven Alemania", como son los escritores de novelas: Kind, Tieck, Wackenroder, Hardenberg (Novalis), Arnim, Brentano, Hoffmann, Häring, Chamisso, Fouqué, Steffens, Zschokke, Schefer, Immermann, Mörike, Stieglitz, Seidl, Ebert, y los autores que se distinguen por una mezcla de humor, de polémica, política y poesía: Heine, Menzel, Börne, Mundt, Laube, Wienbarg, Gutzkow, Kühne, Willkomm, Dingelstedt, Wihl, Marggraff, Schlesinger, Walesrobe, Marlow, Pückler-Muskau, la condesa Hahn-Hahn, Feuerbach, Prutz, la señora Arnim, Rabel, \&c [sic]. (p. 143).
\end{abstract}

Es importante destacar que ninguna de las obras de los autores enlistados figura en la antología. Hassey prefirió incluir autores de reconocimiento indiscutible como Goethe, Lessing o Schiller.

La situación esbozada cambió hacia la década de 1870. El desarrollo de la industria propiciado con la Restauración de la república fue benéfico para el aprendizaje del alemán como una herramienta de acercamiento a la tecnología. En ese momento también ocurrió la aparición de obras literarias influidas por las nuevas corrientes estéticas. Para esta etapa es importante el reconocimiento que hizo Ignacio M. Altamirano de la labor de Luis Martínez de Castro, José Sebastián Segura y Rafael de Zayas Enríquez, principales difusores de la literatura en ese idioma en el país (Altamirano 1988: 150), en su artículo "Revistas literarias de México (1821-1867)", publicadas en el folletín de La Iberia, del 30 de julio al 4 de agosto de 1868 .

\title{
II. E. T. A. Hoffmann en México
}

Como se ha visto, en la difusión de escritores alemanes en territorio mexicano, Francia y España tuvieron un papel fundamental. El caso de Hoffmann, aunque muestra algunas particularidades, no difiere de los casos descritos en el apartado anterior ya que se inserta en el mismo proceso de circulación de libros. Como se ha dicho, los procesos de recepción comenzaron en comenzaron a partir de 1828 en Francia y de la década de 1830 en España. La demora en el caso mexicano puede tener su explicación en el contexto de publicación español, que afectó no sólo la circulación de obras de este autor sino de las obras pertenecientes al movimiento romántico europeo. La llamada "Década ominosa" (1823-1833), es decir, el periodo de la historia de España marcado por el regreso de Fernando VII al trono y el endurecimiento de la censura fue decisivo para ello. Esta situación comenzará a cambiar tras el deceso del monarca (1833); periodo al que precisamente corresponden las primeras muestras de literatura romántica española. Prueba de este cambio es el rápido aumento de las publicaciones periódicas a partir de ese momento, como lo documenta Rodríguez Gutiérrez (2004: 147-157). A este factor habrá que añadir la inestabilidad del contexto de recepción, en el que se sucedían conflictos internos y externos: a la lucha por poder se sumaron los problemas bélicos, entre ellos, el intento de reconquista de Barradas (1829), la guerra con Texas (1835-1836) y la Guerra de los Pasteles (1839). Estas circunstancias explicarían que la difusión de la obra de Hoffmann en México haya comenzado a ocurrir en 1840, década a la que pertenecen las primeras referencias a él y a la particularidad de sus obras.

El 1 de enero de 1841, C. Díaz, publicó en el Repertorio de Literatura y Variedades (p. 259), la obra titulada "Un cuento de vieja", narración en la que se menciona al escritor alemán: "Ni Goya pudo 
imaginar en sus ratos de inspiración un grupo tan pintoresco como el que formaba esta colección de entes atezados y miserables, ni Hoffman [sic] en sus momentos de embriaguez soñar tamaños abortos como los que narró a su auditorio la respetable posadera con una gravedad doctoral”. El comentario es interesante: además de mostrar la preeminencia del relato oral, el autor expresa valoraciones de carácter estético e incluso moral, muy probablemente pervivencia de los juicios ad personam emitidos por Walter Scott, quien fue uno de los principales detractores de Hoffmann en su ensayo "On the Supernatural in Fictitious Composition; and particularly on the Works of Ernest Theodore William Hoffman[n]" publicado en el Foreign Quarterly Review, julio-noviembre, 1827 (pp. 60-98). En dicho texto el escocés manifestó su oposición al uso que daba el alemán a los elementos sobrenaturales, a quien se encarga de denostar tomando como base su alcoholismo y supuesta locura ${ }^{7}$. Scott afirma sobre las obras de Hoffmann: "This may be called the FANTASTIC mode of writing, in which the most wild and unbounded licence is given to an irregular fancy, and all species of combination however ludicrous or however shocking, are attempted and executed without scruple" (p. 72). El texto del autor de Ivanhoe difundido en forma resumida apareció como "Du merveilleux dans le roman", en Revue de Paris, 12 de abril de 1829 (pp. 25-33) y luego formó de parte las Oeuvres complètes de Hoffmann traducidas por François Adolphe Loève-Veimars (París: Impr. de Eugène Renduel, 1829-1836) en el que apareció con el título "Sur Hoffmann et les compositions fantastiques". La irregularidad que adopta la fantasía en estas obras, según Scott, concuerda con los "abortos" producidos por el sueño etílico, a los que se refiere Díaz, quien si bien no necesariamente debió leer el texto, presenta la misma idea. Esta primera referencia muestra algunos de los juicios y prejuicios que circulaban en México al respecto de este autor.

Gracias al anuncio titulado "Libros baratos de ediciones modernas españolas" de la librería ubicada en Joya 3, publicado por El Siglo XIX, en su edición del 17 de octubre de 1842 (p. 4) ${ }^{8}$, es posible comprobar que ya en ese año circulaba en el país el libro Cuentos fantásticos realizada por Cayetano Cortés (Madrid: Imprenta de Yenes, 1839), la primera recopilación aparecida en España (Roas, 2002: 102). Si bien el título remitía a la primera serie de traducciones publicadas en 1829, en la que "ya se llama la atención sobre la relación de Hoffmann con el género fantástico (y que le acompañarán siempre, tanto en Francia como en España)" (Roas, 2002: 54), con excepción de “Aventuras en la noche de San Silvestre", su contenido no es representativo del género al que alude9:

\footnotetext{
${ }^{7}$ Al respecto señala que si bien se trataba de un hombre de "rare talent", esto presentaba serios inconvenientes: "but unhappily of a hypochondriac and whimsical disposition, which carried him to extremes in all his undertakings; so his music became capricious, - - his drawings caricatures, - and his tales, as he himself termed them, fantastic extravagances" (p. 74). Otro fragmento muy elocuente sobre esta mirada desfavorecedora: "But that which is to the person whose mind is in a healthy state, but a transitory though disagreeable feeling, becomes an actual disease in such minds as that of Hoffmann, which are doomed to experience in too vivid perceptions in alternate excess, but far most often and longest in that which is painful, - the influence of an over-excited fancy. It is minds so conformed to which Burton applies his abstract of Melancholy, giving alternately the joys and the pains which arise from the influence of the imagination" (p. 79).

${ }^{8}$ El anuncio aparece nuevamente un par de años después: "Comedias y libros nuevos", en El Siglo XIX, 21 de marzo de 1844 (p. 4); 4 de abril de 1844 (p. 4) y el 2 de mayo de 1844 (p. 4).

${ }^{9}$ Además de la obra mencionada, la antología incluye "Salvador Formica" ("Signor Formica”), "Maese Martín el tonelero y sus oficiales", "Mariano Falieri" ("Dux y la dugaresa"). Los textos en su mayoría pertenecen a Phantasiestücke in Callots Manier (1814-1815). La publicación de la traducción de Cayetano Cortés suscitó algunas reacciones el mismo año de su
} 
"Los elementos fantásticos que aparecen en ellos tienen muy poca importancia tanto en lo estructural como en lo temático" (Roas, 2002: 54). Es importante señalar que el lector no estaba ante una traducción directa sino de una que procedía de la francesa de Loève-Veimars (1829-1836), la más importante de la época ${ }^{10}$.

\section{1. Las traducciones de José María Roa Bárcena}

En 1845 apareció "Haimatocare", la primera de las traducciones que el escritor José María Roa Bárcena dedicó a la obra de Hoffmann, en Museo Mexicano, 1 de enero de 1845 (pp. 268-273) ${ }^{11}$. El texto mantenía el título original "Haimatochare" (1819) procedente de uno de los volúmenes que conforman Die letzten Erzählungen von E. T. A. Hoffmann (Berlín: Bei Ferdinand Dümmler, 1825) obra publicada por Julius Eduard Hitzig, amigo de Hoffmann y su primer biógrafo. La inexistencia de alguna edición española anterior a la de Roa Bárcena (Roas, 2002), permite comprobar que el mexicano se adelantó a las traducciones peninsulares e incluso a la de Champfleury (1856) ${ }^{12}$.

La obra en cuestión se presenta como una serie de cartas que le fueron entregadas al narrador por su amigo Adelbert von Chamisso en las que se refiere una historia de tintes absurdos: El descubrimiento, durante una expedición con destino a O-Wahú, de un extraño insecto al que han bautizado como Haimatochare tiene como consecuencia que un par de amigos naturalistas se batan a duelo y ambos mueran. El texto presenta el caso como si la posesión del insecto se tratara de la pelea por una mujer. El final, por demás paródico, muestra la ejecución al insecto, que es arrojado dentro de una caja al mar entre las salvas de honor de la tripulación y los cantos fúnebres de los aborígenes. En este caso, la singularidad del incidente venido de Chamisso, autor con intereses estéticos afines a Hoffmann, es un homenaje y recurso para bordear el absurdo y lo grotesco. Resulta interesante preguntarse la razón que llevó a traducir una narración que se considera marginal dentro del conjunto de la obra del alemán. A pesar de que el texto se aleja de los inquietantes relatos de Nachtstücken (1817), algo de la exageración y la ironía habitual de Hoffmann están presentes en ella. Para responder a esta cuestión resulta especialmente útil el texto que precedió las otras dos traducciones de Roa Bárcena $^{13}$, aparecidas entre 1855 y 1856 en el periódico La Cruz, que estuvo bajo su dirección:

aparición en España debidas a las plumas de Salvador Bermúdez de Castro, Enrique Gil y Carrasco, y un autor anónimo de El Semanario Pintoresco Español. En ellas se analiza el estilo y los rasgos característicos del autor. Una descripción detallada de estas críticas puede encontrarse en Roas (2002: 93-113).

${ }^{10}$ Teichman (1961) considera que la traducción de Loève-Veimars fue la más leída de la época. Pérez Gil (1993: 229) ha hecho notar que esta obra intenta adaptar a Hoffmann al gusto francés de la época, por lo que presenta algunas modificaciones, entre las que se encuentran la elisión de descripciones que ridiculizan a los personajes y la dilución del carácter fantástico de algunas de las historias.

${ }^{11}$ Posteriormente se publicó con el título de "Haimatocara", en Obras I. Cuentos originales y traducidos. México: Imp. de Victoriano Agüeros, 1897 (pp. 397-424). Ha sido recogido en Hoffmann (2006).

12 Contes posthumes d'Hoffmann. Trad. de Champfleury. París: Michel Lévy Frères, 1856. Esta edición se encuentra conformada por varios ensayos críticos, cuadernos de notas, dibujos, correspondencia y diarios. Además de estar formado por algunos cuentos que hasta entonces habían permanecido inéditos, la obra rescata la faceta musical del autor, representada por algunas de sus partituras.

13 José María Roa Bárcena, "Hoffmann y sus cuentos”, en La Cruz, 1 de noviembre de 1855, pp. 21-22. 
La literatura alemana, cuando no se extravía en las altas regiones de la metafísica, tiene un sello de ternura y belleza que parece peculiar de los climas septentrionales. Prueba de ello son la mayor parte de los cuentos fantásticos de Hoffmann, que, si bien publicados con anterioridad, no vinieron a crearle una reputación europea sino por el año de 1814. Tenemos de ellos una excelente traducción hecha al idioma francés por Marmier, el mismo literato que tradujo y recopiló en cuatro volúmenes de "Cantos populares del Norte" ${ }^{14}$. Como el conocimiento de las obras de Hoffmann se halla en nuestro país circunscrito a los literatos, vamos a traducir al castellano y a insertar en la sección de variedades de este semanario dos de los más hermosos cuentos, siendo uno de ellos "La dicha en el juego" y el otro "Maese Martín y sus obreros".

Varias causas nos inducen a escoger estos dos cuentos: en ellos nada hay de sobrenatural, y esto ya es una garantía de que agradarán a nuestros lectores más bien que aquellos en que domina lo fantástico, muy poco admitido en la literatura moderna de los pueblos meridionales (p. 22).

Además de contener el criterio que pudo haber motivado la publicación de "Haimatocare", la nota contiene algunos datos que permiten obtener más detalles del contexto de recepción. De acuerdo con ella, para la fecha de la publicación de las traducciones del veracruzano, la obra de Hoffmann seguía sin llegar a un público amplio, motivo principal para difundir su obra. La selección responde a un criterio estético basado en la existencia de públicos con sensibilidades diferentes, la pertenencia del público mexicano a la meridional, hecho que determinaba que no fuera propenso a los elementos sobrenaturales; y también a un criterio ético, que privilegiaba lo mimético y lo moral, un aspecto que en el caso del traductor puede responder tanto a la idea de lo que debería ser la literatura nacional, como a la afinidad y vínculo con las concepciones estéticas de Walter Scott ${ }^{15}$.

Otro dato relevante que aporta esta nota es su conocimiento sobre la edición de Xavier Marmier, Contes fantastiques publicada en 1843 y reeditada en 1866 (Roas, 2002: 46); de ella, Martínez (2011: 60) afirma que "existe una versión española publicada en 1850 que probablemente también circularía en América". Aunque esto no ha podido ser corroborado, la edición en español a la que se refiere Martínez debe ser Cuentos fantásticos, precedidos por su vida, escrita por X. Marmier (Madrid: Imprenta de Gabriel Gil, s.a.). Roas (2002: 57) ha señalado que el título y la introducción del germanista francés corresponden con esta traducción ${ }^{16}$. La edición francesa de Marmier, es especialmente importante debido a que, como se verá más adelante, es la fuente de las traducciones que aparecieron en La Cruz.

La primera de ellas es "La dicha en el juego"17 ("Spielerglück"), obra publicada originalmente en Serapionsbrüder (1819-1821). En ella se narra la historia de un joven barón alemán caracterizado por su buena fortuna, quien decide probar suerte con los juegos de azar. Es seguido insistentemente

\footnotetext{
${ }^{14}$ La obra a la que se refiere es Chants populaires $d u$ Nord (París: Charpentier, 1842); incluye textos antiguos y modernos procedentes de Islandia, Dinamarca, Suiza, Noruega, las islas Feroe y Finlandia, junto con algunas imitaciones en verso.

${ }^{15}$ El escocés encarnó la reconciliación de los principios cristianos con la ficción sobrenatural, así como el estrecho vínculo entre el relato histórico y el interés por el rescate regional. Es posible constatar que el veracruzano siguió los pasos de Scott, quien se dedicó a recopilar baladas de su tierra en Minstrelsy of the Scottish Border (1802-1803); Roa Bárcena también hizo lo mismo en el volumen Leyendas mexicanas, cuentos y baladas del norte de Europa y algunos otros ensayos poéticos (México: Agustín Masse-Librería Mexicana, 1862), libro de textos originales y traducciones en cuyo prólogo afirma que para darle un carácter distintivo a las diferentes literaturas "no queda más arbitrio que recurrir a la historia y a las tradiciones especiales de cada país" (p. 6). En sus obras narrativas más conocidas, Noche al raso y "Lanchitas", el veracruzano empleó el material legendario como fuente de inspiración.

${ }^{16}$ Los textos que contiene esta edición son "Le violon de crémone", "Les maîtres chanteurs", "Le majorat", "Maitre Martin et ses ouvries", "Le bonheur au jeu", "Le choix d'une fiancée", "Marino Falieri”, "Don Juan" y "La voeu”.

17 "La dicha en el juego", en La Cruz, 1 de noviembre de 1855 (pp. 23-27), 15 de noviembre de1855 (pp. 86-92) y 29 de noviembre de 1855 (pp. 148-154).
} 
por un extranjero durante varias noches. Después de ser rechazado con rudeza y de haber aceptado las excusas de su ofensor, el hombre intenta convencer al barón de abandonar el juego. Para lograrlo, le cuenta lo que le sucedió a M. Ménars, personaje cuya suerte en el juego lo convirtió en dueño de una banca. Al intentar cobrar las deudas de un anciano conoció a su hija y a causa del amor que sintió por ella decidió perdonar la deuda. Al poco tiempo se hizo novio de la joven y, a la muerte del padre, se casó con ella. Sin embargo, la pareja estaba lejos de ser feliz porque él retomó su pasión por el juego, además de que era atacado en todo momento por los celos que le despertaba Dovernet, un joven con el que ella creció, quien al poco tiempo se unió a un regimiento destinado a España. El suicidio de un jugador trajo a Ménars el descrédito y tuvo que abandonar París e irse a Génova, donde perdió su fortuna ante un coronel inválido dueño de la banca más rica del lugar. Fue orillado por su rival a apostar a su esposa. Tras ser vencido, Duvernet le reveló que había caído en una trampa. Cuando se dirigen con la joven, ella estaba muerta. El militar salió horrorizado. Ahí concluye el relato del extranjero, quien muere días después. El barón queda agradecido por el favor que el hombre, en quien ha reconocido a Ménars, le ha prestado.

Como puede comprobarse en esta síntesis, la trama carece de elementos sobrenaturales y su finalidad es alertar a los lectores sobre las consecuencias de la ludopatía. Sobre él, Roa Bárcena señala que:

"La dicha en el juego" encierra gran suma de moralidad, y su adopción para nuestras columnas cumple el objeto que nos hemos propuesto al publicar este periódico: el juego es uno de los vicios, por desgracia, más arraigados en nuestra sociedad, y la obrita de Hoffmann puede señalar elocuentemente a muchos jóvenes el escollo que deben evitar y que ha sido y es la ruina de innumerables familias y la muerte de muchas esperanzas fundadas en el mérito de los individuos a quienes el juego corrompe y aniquila (p. 22).

De este cuento destaca el siguiente fragmento en el que se presentan las reflexiones de Ménars que anteceden a la narración de la historia: "En tales circunstancias el duelo decide quién de entrambos debe hacer lugar al otro sobre la tierra: entonces el duelo es necesario". Su interés radica en la nota a pie de página que la acompaña, en la que Roa Bárcena da a conocer su opinión y se aparta de las de los personajes: "No estamos conformes con esta doctrina, y nos proponemos más adelante tratar la materia con alguna extensión (N. de T.)" (Primera entrega, p. 25). La aclaración deja ver que, al igual que la escena brutal, en la que un joven jugador se suicida delante de la concurrencia, había aspectos del texto original que escapaban al cuidado moral del traductor y cuya publicación necesitaba ser acompañada de explicaciones dirigidas al público.

El cotejo entre las diferentes publicaciones tanto francesas como españolas permite demostrar que esta traducción proviene de la edición de Marmier ${ }^{18}$. Además de la división en capítulos y la disposición de párrafos existen otros elementos que lo constatan: 1) Tanto en la traducción francesa

\footnotetext{
${ }^{18}$ Aunque la obra aparece en las traducciones francesas de Loève-Veimars (1830) y de Henry Egmont (pseud. d'Henri Massé) (1840) existen pruebas de que el texto está tomado de Xavier Marmier, Contes fantastiques d'Hoffmann, editado por Charpentier (1852 y 1866). La obra apareció en España con los títulos "Fortuna en el juego" y "Afortunado en el juego" pertenecientes a Obras completas de E. T. A. Hoffmann. Cuentos fantásticos (Barcelona: Imprenta de Llorens hermanos, 1847); y a Cuentos fantásticos (Barcelona: Carbonell y Esteva editores, s.a. [1850?], pp. 135-335). Estas difieren de la traducción de Roa Bárcena.
} 
como en la del mexicano el Barón Siegfried está al servicio del príncipe de Hesse, dato que no aparece en el texto original; 2) La apuesta que lleva al personaje a convertirse en un jugador consumado lo hace ganar mil luises, que en la edición francesa y en la mexicana han cambiado a 20 mil; 3) En el texto francés y en el de Roa Bárcena, Ménars muere de apoplejía, enfermedad que no aparece mencionada en el original; 4) Tanto la edición francesa como la mexicana eliminan un fragmento, que se refiere al dios Mammón, vinculado a la ambición y al dinero; en este caso, probablemente se consideró que la referencia era demasiado críptica para los lectores.

La otra traducción de Roa Bárcena es "Maese Martín y sus obreros"19 ("Meister Martin der Küfner und seine Gesellen”), texto perteneciente a Serapionsbrüder (1819-1821). Aunque el texto aparece como "Maître Martin le tonnelier, et ses Apprentis" en la de Loève-Veimars (1830) y "Maître Martin le tonnelier et ses apprentis" en la de Egmont $(1840)^{20}$, la traducción de Roa Bárcena proviene de "Maître Martin et ses Ouvriers", perteneciente a la misma edición de Marmier que el texto anterior. La obra de Hoffmann posee subtítulos, pero el primero de ellos está acortado en la edición francesa: "Comment maître Martin fut élu syndic", situación que también se presenta en la del veracruzano. Al igual que en la edición francesa, el texto de Roa Bárcena suprime las alusiones a cuestiones específicas del ámbito alemán, sobre todo relacionados con música: lied, la alusión al canto delicado al modo de Martin Harcher, el modo de Hans Vogel, el tono dulce, el modo del corno, el florido modo del paraíso, el fresco modo de la naranja. Es importante señalar que los títulos de las ediciones españolas difieren del que escogió Roa Bárcena ${ }^{21}$.

La trama es la siguiente: Ante la idea de casar a su hija, Maese Martín, el tonelero más exitoso de Nuremberg, está convencido, por la profecía que la abuela hizo antes de morir, de que la joven debe contraer matrimonio con el mejor tonelero. De entre los pretendientes tres son los candidatos que fingen estar interesados en el oficio del suegro para obtener la mano de la joven: Friedrich, habilidoso orfebre, Reinhold, excelente cantor y pintor, y el impetuoso y franco Conrad, quien se revelará hijo de un amigo del maestro. Al final ella elegirá al primero, con quien creció y del que estaba enamorada.

Al igual que el caso anterior, la obra no tiene rasgos fantásticos, aunque la distorsión caricaturesca lo acerca a lo grotesco. El traductor señala que "aunque carece de un objeto moral tan directo como la obra anterior, lo encierra indudablemente en la pintura animada de la vida doméstica y de los afectos más nobles y tiernos. Aparte de esto retrata con la mayor fidelidad las costumbres

\footnotetext{
19 “Maese Martín y sus obreros", en La Cruz, 20 de diciembre de 1855 (pp. 256-258), 27 de diciembre de 1855 (pp. 286 291), 3 de enero de 1856 (pp. 320-323), 10 de enero de 1856 (pp. 348-351), 24 de enero de 1856 (pp. 408-413), 7 de febrero de 1856 (pp. 480-484), 21 de febrero de 1856 (pp. 548-552), 28 de febrero de 1856 (pp. 578-581), 6 de marzo de 1856 (pp. 604-609). El texto que aparece en Hoffmann (2006) está incompleto, carece del capítulo en el que se conocen Friedrich y Reinhold de camino a Nuremberg, titulado: "Comment les deus compagnons Frédéric et Reinhold firent connaissance ensemble".

${ }^{20}$ Contes fantastiques de E. T. A. Hoffmann. 4 t. Trad de Henry Egmont [pseud. d'Henri Massé]. París: Perrotin, 1840.

21 "Maese Martín el tonelero y sus oficiales", Cuentos fantásticos (Madrid: Imprenta de Yenes, 1839); "Maestro Martín el tonelero y sus aprendices", en Obras completas de E. T. A. Hoffmann. Cuentos fantásticos (Barcelona: Impr. de Llorens hermanos, 1847) y "El maestro Martín y sus mancebos", Cuentos fantásticos, (Barcelona: Carbonell y Esteva editores, s.a. [1850?], pp. 135-335).
} 
alemanas, y en cuanto a su mérito literario lo han proclamado ya los inteligentes de todos los países" (p. 22).

Conrad, personaje caracterizado por su fuerza descomunal, desparpajo y agresividad, rayando en la caricatura rabelesiana, sirve como contrapunto a los otros pretendientes. Precisamente él participa en el siguiente fragmento en el que se introducen elementos de irracionalidad, un efecto que el autor consigue al no brindar toda la información al lector y revelar las intenciones del personaje hasta el final, rasgo presente en varias obras de Hoffmann:

Maese Martín, con los brazos cruzados a la espalda, adelantado el pie izquierdo, y la cabeza echada hacia atrás, dirigió una mirada radiante al tonel y dijo con orgullo: "Querido Maese Holzschuer, al ver lo escogido de esta madera y lo esquisito [sic] del trabajo, habríais debido comprender que un tonel semejante sólo podía estar reservado a una cueva de príncipe. Reinaldo ha dicho muy bien; no pidáis una obra como ésta, mas luego que terminen las vendimias, os haré un buen tonel, tan sólido como se necesita para vuestra cueva."

El viejo Holzschuer, irritado con el orgullo de Maese Martín, pretendió que sus monedas de oro pesaban lo mismo que las del obispo de Bamberg, y que, mediante su dinero, en cualquier otro taller hallaría un tonel tan bueno como el reservado al obispo.

Maese Martín apenas pudo contener su cólera; no osaba ofender al digno Holzschuer, estimado del consejo y de todos los vecinos. En este mismo instante Conrado batía sobre las duelas con tal fuerza que retumbaba todo el taller. La cólera de Maese Martín estalló contra él y exclamó con violencia: “Conrado de todos los diablos, ¿por qué pegas así? ¿tratas acaso de romper mi tonel?

— ¿Por qué no? Contestó Conrado, mirándole con audacia; ¿por qué no maestrito? Y al decir estas palabras redobló sus golpes de tal manera que los aros se reventaron y las duelas derribaron a Reinaldo del andamio en el que estaba sentado.

En el arrebato de su furor, Maese Martín se apoderó de un palo que tenía Valentín en la mano, y dio con él a Conrado en la espalda, diciéndole: “¡Toma, perro maldito!”

No bien Conrado recibió el golpe cuando se volvió vivamente, y por un instante permaneció como petrificado; en seguida se le inflamaron los ojos, rechinó los dientes y exclamó: “¿Pegarme a mí?” Al decir esto, de un salto recogió una hacha que estaba en el suelo, y dirigió con ella un golpe tan vigoroso a Maese Martín, que le habría abierto la cabeza si Federico no hubiese empujado hacia atrás al tonelero, de modo que el hacha solamente le hirió el brazo, de donde comenzó a brotar sangre. Maese Martín perdió el equilibrio y vino al suelo. Todo el mundo se echó sobre el furioso Conrado, quien agitando su hacha ensangrentada en el aire, exclamaba con voz terrible: "Preciso es que yo le envíe a los infiernos", y rechazando con fuerzas de gigante a todos aquellos que lo rodeaban, iba a dar a Martín, tendido en tierra, un segundo golpe, que hubiera acabado con él, cuando súbitamente se apareció Rosa en la puerta del taller, con el semblante pálido y asustado.

Tan luego como Conrado percibió a Rosa, se quedó con el hacha en la mano, inmóvil como una estatua; en seguida, arrojando el arma lejos de sí, juntó sus manos sobre el pecho y exclamó con acento que conmovió a todo el mundo: “¡Oh Dios del cielo! ¿qué es lo que he hecho?” Después se salió del taller y nadie pensó en seguirle (pp. 550-551).

Aunque "La dicha en el juego", "Maese Martín y sus obreros" y "Haimatocara" no son los cuentos más representativos del autor alemán junto con la nota introductoria en el periódico católico La Cruz integran un testimonio esclarecedor del proceso de recepción y circulación de las obras de Hoffmann hacia mediados del siglo XIX.

\section{2. Ignacio Manuel Altamirano y Hoffmann}

La relación que se estableció entre la obra del alemán y la de Ignacio Manuel Altamirano aporta más claves sobre la circulación de este autor. Resulta de especial interés el comentario que le dedica a 
este autor y a la literatura fantástica en "Revistas literarias de México (1821-1867)" 22, texto valioso para conocer la situación de la literatura en la época en el que es posible verificar que para el periodo de la República Restaurada, el segundo romanticismo, el autor había cobrado una notoriedad que no estaba presente al momento de la publicación de las traducciones de Roa Bárcena. Altamirano destacó su novedad y consideró al alemán cabeza de una escuela:

Una nueva escuela, alemana por cierto, ha añadido todavía a la forma romanesca un atractivo más: lo fantástico; a que son tan inclinadas las imaginaciones del norte. Pero lo fantástico de cierta especie, no lo fantástico de los pueblos primitivos que es común a todos los países y que ha nacido del terror religioso y la ignorancia, sino de lo fantástico ideal, si podemos expresarnos así. Hoffman es el padre de esta escuela, que se ha seguido en Francia y en que se han hecho débiles ensayos en España. Los cuentos de Hoffman han adquirido gran celebridad, y nosotros no los admiramos tanto por su originalidad, como por su exquisito sentimiento (Altamirano, 1988: 55).

La mayor prueba de su interés por el autor se puede encontrar en Clemencia (1869), la primera novela del guerrerense, en la que dos citas procedentes de obras del alemán sirven de arranque a la narración (Altamirano, 1986: 158). La primera pertenece a "El corazón de Ágata” ("Das steinerne Herz"): "Ningún ser puede amarme, porque nada hay en mi de simpático ni dulce" "23; y, la otra, a "La cadena de los destinados" ("Der Zusammenhang der Dinge"): "Ahora que es ya muy tarde para volver al pasado, pidamos a Dios para nosotros la paciencia y el reposo..."24. De acuerdo con Gutiérrez de Velasco (2006: 369), estos cuentos pudieron ser leídos en su lengua original o en la traducción, Contes fantastiques de Pierre Christian (París: Lavigne, 1843) ${ }^{25}$. El empleo de esa edición se confirma gracias al cotejo entre el alemán y el francés realizado por Rosado (2015), y también porque, además de coincidir con los títulos dados por Altamirano en Clemencia, es decir, "Le coeur d'agate" y "La chaine des destinés", la edición contiene algunos de los textos a los que se refiere en otros textos, es decir, "Berthold le fou" 26 , y "Coppelius"27.

Los cuentos aludidos en Clemencia no responden al género fantástico, sino más bien a la idea de Altamirano de "exquisito sentimiento" y a los temas que le interesan. "Das steinerne Herz" presenta a la joven Julia en medio del amor de Max y el Consejero de la Corte Reutlinger. Este último pronuncia las palabras citadas por Altamirano al referirse a sí mismo. "Der Zusammenhang der Dinge” presenta

${ }^{22}$ Publicadas en el folletín de La Iberia, del 30 de julio al 4 de agosto de 1868.

${ }^{23}$ De acuerdo con Roas (2002: 253) el texto apareció en las ediciones españolas con el título de "El corazón de piedra".

${ }^{24}$ Roas (2002: 253) señala que en las ediciones españolas de la época aparece con el nombre de "El enlace de las circunstancias".

${ }^{25}$ La publicación cuenta con una edición posterior (París: Morizot, 1861).

${ }^{26}$ La referencia pertenece a "La iglesia de los jesuitas de G*" ("Die Jesuiterkirche in G.") publicado en Nachtstücken (1817): "De otro modo, el cronista, por más entretenido que encuentre ese trabajo infecundo en México, acabará al fin por fastidiarse de él y arrojar la pluma, como Bertoldo el loco del cuento de Hoffman [sic] arroja sus pinceles fatigado del colorido y del eterno embrollo de la tarea" [El subrayado es mío]. I.M. Altamirano, "La vida en México", en El Siglo XIX, 31 de marzo de 1894, p. 1 [Texto fechado en 1880].

${ }^{27}$ La referencia pertenece a "El hombre de arena" ("Der Sandmann") publicado en Nachtstücken (1817): "Estos artistas no tienen ya la brida de la Escuela, ni se sienten detenidos por la barrera de la doctrina, o para valernos de otra expresión, no usan ya los anteojos que les coloca la tradición sobre la nariz y que semejantes a los anteojos de Maese Coppelius el del cuento de Hoffmann, no dejan ver más que la misma muñeca, los mismos vestidos y los mismos gestos por donde quiera y a todas horas" (p. 1). I.M. Altamirano, "El Salón en 1879-1880 (Impresiones de un aficionado)", en La Libertad, 16 de enero de 1880 (pp. 1-2). El texto publicado a inicios de enero, continúa el 14, 16, 18, 24, 27 de enero, 1, 3 y 4 de febrero. El texto ha sido recogido en Altamirano (1989: 129-198). 
la oposición entre el caracter de los personajes: Euchar, retraído, introvertido, soñador; y el extrovertido y fanfarrón Ludwig en un conflicto que se desarrolla en dos planos, el del ser y el del parecer, de la misma manera en la que ocurre en Clemencia. Así, al final del cuento de Hoffmann el lector descubre que el alemán que se ha unido al pueblo español en contra de Francia, cuya historia conocemos por boca de Euchar, es él mismo. Es muy probable que uno de los motivos para que la narración le haya parecido relevante a Altamirano fue que en ella se representaba la anteposición de la libertad de un pueblo por encima de sus intereses personales. Más aún en este caso porque se trata de un joven extranjero. La frase que se cita es pronunciada, por Viktorine, quien se ha dejado llevar por las apariencias; algo que también le ocurre a la protagonista de Clemencia.

De acuerdo con la propia novela, los fragmentos proceden de un libro de cuentos de Hoffmann que llega a las manos del protagonista durante el encierro que precede a su injusto fusilamiento:

Deseo que me haga usted un favor. He escrito esa carta para mi padre. Tenga usted la bondad de enviársela para que sepa que su pobre hijo ha dejado de existir. Hoy me han traído un libro para leer. Eran los Cuentos de Hoffmann. He leído dos; y como un desgraciado busca siempre en lo que lee los pensamientos que están en consonancia con sus penas y sus propias ideas, he copiado en ese papel esos dos; guarde usted ese papel en su cartera, y cuando le vea, recuérdeme. Me es grato pensar que usted me recordará. La memoria de un alma compasiva es la más santa de las tumbas (Altamirano, 1986: 305).

Cabría preguntarse si Altamirano estaba pensando en la misma edición que él leyó, la de Christiane, o en otra.

Fundamental para la suerte del alemán en México, y también para la obra de Altamirano, es la publicación del Álbum de Navidad (1871), antología en la que apareció por primera vez "La navidad en las montañas". El volumen impreso por Ignacio Escalante y Compañía, conformado por esta obra junto con las de Luis G. Ortiz, Manuel Sánchez Mármol, Francisco Sosa, J. Rosas, Manuel Flores, Facundo [Cuellar], José Peón Contreras, González de la Torre y Fidel [Guillermo Prieto], contiene como único texto extranjero "La noche de Navidad" 28 , obra traducida por Manuel Peredo que demuestra el vínculo que se estableció entre la obra de Hoffmann y el tema navideño, fenómeno que también puede responder a la circulación de El príncipe Cascanueces y el rey de los ratones (Nussknacker und Mausekönig), una de sus obras más célebres a este respecto, perteneciente a Serapionsbrüder (1819-1821) y que se ha tendido a leer como un texto autónomo. Le Nuit de Noël es una adaptación hecha por George Sand de Meister Floh (1822), que forma parte de Théâtre de Nohat (1865). Durante la noche de Navidad, a la casa de Peregrinus llega su amigo Max. El lugar es escenario de una serie de sucesos sobrenaturales, como una aparición fantasmal, la animación de un espectáculo de títeres y la presencia de un viejo reloj relacionado con el movimiento perpetuo, que tiene por clímax la extirpación del espíritu que aqueja a Max y la aceptación de la propuesta de matrimonio que Peregrinus le hace a Nanni. El texto publicado en México carece del interesante "Avertissement" en el que la autora, auténtica ferviente de Hoffmann ${ }^{29}$, manifiesta su interés y afición a las obras de este

28 "La noche de Navidad”, en Álbum de Navidad (México: Impr. Ignacio Escalante y Compañía, pp. 49-125). Trad. de Manuel Peredo.

${ }^{29}$ La autora en sus Lettres d'un voyageur declara: "J'eus envie d'aller lui donner des coups de poing, et je pensai à toi, aimable Théodore, facétieux Kreyssler, Hoffmann! poëte amer et charmant, ironique et tendre, enfant gâté de toutes les 
autor $^{30}$. Sitstrup-Jensen (2011: 238), destaca como el motivo principal de su interés el valor experimental que Sand encontró en sus obras: "le genre hoffmannesque est pour elle davantage un lieu conduisant à experimenter par divers modes, formes et genres, c'est-à-dire une modèle d'écriture, ou encore une attitude qui autorise des jeux avec les codes".

La difusión de esta adaptación no sólo es ejemplo de la popularidad de autor, sino de la configuración de nuevos públicos y su modificación debida al cambio de contexto. En su caso el público infantil para el que Sand concibió su obra, en la edición aparecida en México es cambiado por un público adulto. El caso es también un ejemplo destacado del papel legitimador que ejercieron las plumas de los escritores franceses más importantes de la época. Al respecto es importante recordar que tras el ataque de Scott, publicado en Francia en la edición de Loève-Veimars como "Sur Hoffmann et les compositions fantastiques", contrariamente a lo esperado, se generó una abierta animadversión en contra del escocés en defensa de Hoffmann por figuras como el propio Loève-Veimars, Jean-Jacques Ampère, Duvergier de Hauranne, Charles Nodier, Th. Gautier, sólo por mencionar a los más importantes; reacción que contribuyó a la disminución de la popularidad de Scott en el ámbito francés (Castex, 1962: 51). De los autores mencionados, es particularmente significativo para México el caso de Alexandre Dumas, quien haciéndose eco de las Mille et une nuits, puestas de moda por la traducción al francés de Antoine Galland (1704-1717), en su obra Les Mille et un fantômes (1849) quiso demostrar su habilidad en el género fantástico y en varias de sus narraciones se refirió al autor alemán, e incluso lo hizo protagonista de La Femme au collier de velours (1850), novela que circuló en varias ediciones en México en la que el escritor alemán es víctima de una experiencia sobrenatural vinculada con la guillotina durante la época del Terror en París ${ }^{31}$.

Ejemplos de un fenómeno cercano al descrito, aunque ya no con la celebridad del autor de Les trois mosquetiers, son las obras de ficción difundidas en la prensa de la época que retrataban contextos costumbristas en los que los personajes dan cuenta de los modos de leer a Hoffmann. El hecho más

muses, romancier, peintre et musicien, botaniste, entomologiste, mécanicien, chimiste et quelque peu sorcier! (Citado en Castex, 1962: 85-86).

${ }^{30}$ En este preámbulo, la escritora francesa admite su desconocimiento del alemán como para asegurar si M. Loève-Vermars había embellecido el texto (Sand, 1865: 211) y pondera el valor de los cuentos de Hoffmann: "Pourtant il y a toujours dans ces contes, même dans les plus merveilleusement impossibles, des caractères et des situations d'une vérité charmante, des figures d'une simplicité adorable et des traits de mœurs qui offrent de ravissans tableaux. C'est le côté par lequel, soit habileté, soit véritable humour, il vous saisit et vous force à suivre ses personnages à travers le monde de l'hallucination" (Sand, 1865: 212). Sand además trata el problema de la representación en escena de fenómenos asombrosos, que, en su caso, soluciona por medio de la descripción: “Tout ce qui a été ingénieusement produit à la représentation, la scène des jouets d'enfant, l'apparition des petits animaux, l'audition de leurs petits bruits mystérieux, etc., eût fait honneur à la science du Leuwenhoek de Maître Floh; mais l'effet de ces moyens inusités n'était dû qu'à la petitesse du théâtre, à la proximité du spectateur et à l'invention du metteur en scène. C'est pourquoi nous les avons fait apparaître dans notre texte sous la forme descriptive, non pas de la même manière qu'ils apparaissent dans les rêves prodigieux d'Hoffmann, mais sous l'impression que cette vision naïve nous a laissée" (Sand, 1865: 214).

${ }^{31}$ La mujer del collar de terciopelo, apareció como folletín en El Monitor Republicano, 27 de abril al 10 de mayo de 1850 , p. 1. Trad. de M. L. y D. imprenta de Vicente García Torres. Es mencionada en un anuncio de La Patria, 26 de febrero de 1882 (p. 1) o del que apareció en la sección "Libros en venta en las oficinas de La Patria", en La Patria, 13 de septiembre de 1883 (p. 5). Los mil y un fantasmas comenzó a aparecer en El Monitor Republicano, 1 de marzo de 1850 (p. 4) y también en El Mundo, del 27 de septiembre al 28 de diciembre de 1905 (p. 4). A estas publicaciones es necesario agregar también Historia de un muerto contada por el mismo, que también hace constantes referencias al alemán, iniciado en El Chisme, 12 de julio de 1899 (p. 4). 
significativo de estas escenas es que la lectura de obras de este autor se había convertido en un pasatiempo. En esta primera entrega la obra de Margarita Lowed, "Las golondrinas. Cuento de Prelletzo" [Secc. Variedades], en La Voz de México, 27 de agosto de 1879 (p. 2); se afirma lo siguiente:

Siguiendo en dirección recta el empolvado camino, flanqueado de quebradiza y espinosa maleza, llegamos a la puerta de la cabaña; cuyo cobertizo apenas si cubre de trecho en trecho, por sus profundas e irregulares hendiduras, el espacio donde se ven apiñados manojos de sarmientos que han de ser carbonizados más tarde para calentar el hogar de Maese Gualberto, mientras oye leer los cuentos de Hoffman [sic] a su hija Teodomira durante las veladas de la estación de las nieves.

Para los personajes de Margarita Lowed sus obras están vinculadas con el miedo, aunque es preciso aclarar que si bien cultivó el relato gótico, los fantasmas no son lo más representativo de su obra.

Teodomira le dedicó una sonrisa de esas en que los niños pintan la satisfacción de un deseo realizado, y se dirigió nuevamente a su asiento.

Maese Gualberto, en cambio, bajó los ojos con el pudor del hombre que es padre, como si el silencio de su respuesta estuviera agobiado por el peso de amargos presentimientos, de crueles e ignorados infortunios.

- Leeremos a Hoffmann, ¿no es verdad? Dijo aquella boca con cariñoso acento al anciano.

—No... hija mía... vale más que no hablemos de Todos Santos.

- ¿Y por qué no, padre, de los Difuntos? ${ }^{32}$

El siguiente diálogo en el que se enlaza lo maravilloso con lo fantástico y aparece mencionado Hoffmann como representante del segundo, forma parte del relato "Las tres mujeres de Enrique Smirt" de Anais Segalas [sic] traducido por Arturo Paz publicado en La Patria, 13 de julio de 1883, (p. 3):

- Pero estoy persuadida, señor, que he estado en un error... y lo siento mucho.

$-\mathrm{Y}$, espero señora, que de hoy en adelante, cuando queráis referir cuentos fantásticos, os contentéis con escogerlos en Las Mil y Una Noches o en Los Cuentos de Hoffmann.

- ¡Eh! señor, exclamó la marquesa impaciente, quien sabe si el gato Murr no se ofendería.

Mr. de Armangis la vio con un aire grave, y la dijo con un tono de autoridad:

- Me es permitido, señora, exigiros, que no repitáis a nadie esa miserable invención. De otra manera, me forzaréis a recordaros con toda la política posible que la ley es severa para los calumniadores y aún, para las calumniadoras, por encantadoras que sean.

El texto además menciona las Opiniones del gato Murr (Katers Murr, 1819-1821), obra que no fue traducida en México o en España durante el siglo XIX (Roas, 2002). La edición francesa, Les Contemplations du chat Murr, formó parte de la edición de Loève-Veimars (1832). Además de lo mencionado, un personaje de Segalas emite un juicio en contra de la mentira, imperdonable incluso aunque esté revestida de belleza.

\section{3. Ireneo Paz, editor de Hoffmann}

En la imprenta de Ireneo Paz fue publicada La careta de la muerte: novela (México: Ed de La Patria, 1881), obra que es en realidad "El voto" ("Das Gelübde”), texto perteneciente a los Nocturnos

32 [“Las golondrinas"], en La libertad [Folletín], 5 de mayo de 1878 (p. 2). El mismo fragmento apareció en La Voz de México [Secc. Variedades], 28 de agosto de 1878 (p. 2). 
(Nachtstücken, 1817). Gracias a algunos elementos paratextuales de esta edición es posible determinar el origen de la traducción. Aunque "Le Vœu" aparece en las ediciones de Loève-Veimars (1830) y en la de Marmier (1852 y 1866), y no hay constancia de edición española (Roas, 2002), la publicación de Paz corresponde enteramente con la traducción de Émile de la Bédollière, Contes nocturnes d'Hoffmann (París: Gustave Barba, 1856 y 1863) ${ }^{33}$. En esta obra Hoffmann pretende guardar el anonimato de los personajes, sólo dejando que el lector conozca sus nombres y la primera inicial de sus apellidos; un recurso que le permitió dotar a su narración de mayor verosimilitud y referirse a ellos como si se tratara de personas reales. Este aspecto ha sido clave para identificar la edición francesa de la que este texto procedía, ya que la traducción de Bédollière es la única que inventa la información omitida en el original y le da nombre completo a lugares y personajes, como sucede con la edición de Paz; en ella, la acción se desarrolla en Lilinitz, y los personajes son el príncipe Zampolski, los condes Népomucène de Czernski, Stanislas de Ramskay y Xavier de Ramskay. Sin embargo, es importante destacar que, aunque la edición mexicana presenta estos nombres castellanizados y la misma división de capítulos de la traducción francesa, que no está presente en la obra original, agrega un título a cada uno de ellos.

El cambio de título sirve para dirigir el punto de interés hacia la máscara, más que en el voto que ésta representa ("Nunca verá de nuevo el mundo el rostro cuya belleza sedujo al diablo" [p. 576]). El subtítulo "novela", añadido por el editor, es clara evidencia de una lectura del texto original explica las adaptaciones realizadas con la finalidad de ajustarse a las expectativas de los lectores de este género $^{34}$. Aunque, a decir verdad, el texto no es más extenso que otras obras del autor consideradas "cuento" revisadas anteriormente como es el caso de "Maese Martín y sus obreros", los títulos de capítulos tienen una función de síntesis para un texto cuya estructura podía resultar confusa ${ }^{35}$.

En este caso, la historia comienza planteando un misterio: A la residencia del alcalde de la ciudad polaca de L. llega una carroza que trae a dos mujeres, una monja y una joven que cubre su rostro con un velo. El funcionario sabe que la ha enviado el príncipe Z. La joven tiene un hijo. Un día llega un jinete e irrumpe para verla. Al quitarle el velo descubre una máscara. Se lleva al niño afirmando que es su hijo. Llega una carroza del príncipe cuando ya es demasiado tarde y el hombre ha escapado.

\footnotetext{
33 Obra integrada por "Le majorat", "Ignace Denner", "Le Sanctus", "L’homme su sable”, "La femme vampire”, "La maison déserte", "L’église des jésuites", "L’élève du grand Tartini”, "La vœu”, "Le cœur de pierre”, "Les espions" y “Le diable à Berlin",

${ }^{34}$ Este problema, al respecto de la extensión de los "cuentos" de Hoffmann, ha sido planteado también por Altamirano en una nota final de Clemencia, en la que se pregunta por la diferencia entre el cuento y la novela corta: "El menor de los defectos de esta pobre novelita, es que para cuento parece demasiado larga. Pero no hay que tomar formalmente la ficción de que el doctor relate esto en una noche. Es un artificio literario, como otro cualquiera, pues necesitaba yo que el doctor narrara, como testigo de los hechos, y no creí que debía tener en cuenta el tamaño de la narración. Además, a pesar de mi pequeñez, me amparan, para hacer perdonable lo "largo del cuento", los ejemplos de Victor Hugo en Bug-Jargal, de Dickens en varios de sus Cuentos de navidad, de Erkmann-Chatrian en sus Cuentos populares, de Enrique Zschokke en sus Cuentos suizos, y de Hoffmann en muchos de los suyos. En lo que sí no tengo amparo es en lo demás, y no me queda más recurso que apelar a la bondad de los lectores" (Altamirano, 1986: 311).

${ }^{35}$ Los títulos de capítulos son los siguientes: "La desconocida", "El parto y el bautizo", "El rapto del niño", "Ojeada retrospectiva", "Javier de Ramskay", "El mensajero del amor", "Fidelidad prometida”, "Situación singular”, "Aclamación del misterio" y "Horrible voto".
} 
La historia se cuenta posteriormente: Hermenegilda von C, hija del Conde Nepomuk von C., comparte el patriotismo polaco con su padre. En una de las reuniones a la que invita a los adeptos a la misma causa, conoce al Conde Stanislaus. La pareja entabla amistad. El joven va a la guerra. Al tiempo llega su primo Xaver, quien trae noticias de él. Xaver se empeña en tomar el lugar de Stanislaus en el corazón de ella sin éxito, hasta que aprovechando un momento de delirio de la joven que cree ver en él a su amado, tiene relaciones con ella y la embaraza.

La obra en cuestión es un ejemplo de la intervención del editor y su papel en la reinterpretación de obras literarias.

\section{4. La ópera y Manuel Gutiérrez Nájera}

Importante dentro del proceso descrito, debido al interés que suscitó en el público mexicano fue el estreno de la ópera compuesta por Jacques Offenbach, Les Contes d'Hoffmann, que tuvo lugar en el Gran Teatro Nacional el 15 de diciembre de $1882^{36}$, acontecimiento que encontró respuesta del público y de la crítica. La más importante de ellas correspondió a Manuel Gutiérrez Nájera, El Duque Job en "Los cuentos de Hoffmann" aparecida en las páginas de La Libertad, 21 de diciembre (p. 2). En ella, el crítico implacable de las obras de Offenbach, reconoce el esfuerzo del compositor y considera que la obra es una excepción, dada su pertenencia a una etapa en la que los trabajos del compositor "se diferencian de sus primeras obras bufas y se acercan a la buena música francesa". El "melodrama" escrito por Barbier y Carré, mereció su rechazo debido a que en su opinión "los libretistas han hilvanado con un hilo burdo y grueso". Gutiérrez Nájera menciona los títulos de tres de los cuentos que conforman esa obra: "Maese Coppelius", "El violín de Cremona" y "Don Juan”, declaración que deja ver que muy probablemente el Duque Job los conocía por la traducción de Marmier, en la que aparecen precisamente con esos nombres.

Otro aspecto importante de este artículo es que Gutiérrez Nájera utiliza la denominación "Los cuentos fantásticos de Hoffmann", lo que permite comprobar que estaba al tanto de la novedad y especificidad de la narrativa hoffmaniana. Asimismo, una prueba de que el escritor conocía el proceso de recepción del autor en Francia es que su texto inicia con una cita de Théophile Gautier, en la que el autor de Émaux et Camées afirma que la popularidad del alemán era mayor en Francia que en su propio país, aun cuando advierte que el "francés no es dado a fantasías por su naturaleza". Gutiérrez Nájera concuerda con esta idea y cita: "la media luz, tan necesaria a lo fantástico, no existe en Francia ni en el pensamiento, ni en la lengua ni en las casas. Los cuentos de Hoffmann son incompatibles con nuestros pensamientos volterianos, nuestras lámparas de cristal y nuestras grandes ventanas”37. El

\footnotetext{
${ }^{36}$ La ópera, compuesta por Jacques Offenbach (1819-1880), basada en el libreto de Jules Barbier y Michel Carré se estrenó en la Opéra-Comique el 10 de febrero de 1881.

${ }^{37}$ Este fragmento pertenece a "Contes d'Hoffmann”, en Chronique de Paris, 14 de agosto de 1836 (pp. 441-447). El texto, publicado sin la parte final en su primera versión, apareció con el título de "Études littéraires. Hoffmann" en Musée des Familles (1841) y en 1874 en la edición de Charpentier de Contes d'Hoffmann. El texto completo se encuentra en Souvenirs de théâtre, d'art et de critique de Théophile Gautier (1883) publicada en París por Charpentier (Spoelberch de Lovenjoul, 1968: 93).
} 
comentario es importante porque muestra una transformación que vendría a matizar la teoría, ampliamente difundida, de que el clima influía en las manifestaciones culturales de los pueblos, ya que en este caso, para la época a la que se refiere Gutiérrez Nájera, Francia ya había adoptado la sensibilidad septentrional.

Manuel Gutiérrez Nájera consideró el tema del enamoramiento de una autómata, referencia a Der Sandmann, trágico y de una verdad profunda. Para él, todos los hombres se podían identificar con él, porque las mujeres "son muñecas conscientes; tienen uñas; chupan la sangre, como los vampiros, y matan con su amor, como el manzanillo con su sombra". Considera que las mujeres de Hoffmann son "símbolos dramáticos". No reconoce en Stella un símbolo, sino el opuesto de Olimpia y Antonia; es decir, una representación de la vulgaridad del mundo cotidiano. Con ello, da cuenta de uno de los puntos más importantes de la concepción del arte de Hoffmann, quien en todo momento trataba de escapar del mundo cotidiano.

Así pues, sus comentarios muestran que era consciente de que las obras de Hoffmann eran más complejas de lo que la ópera dejaba ver, y sin embargo reconocía que algunas de sus verdades etéreas y nocturnas se percibían en la obra. También es un ejemplo de la adaptación interartística digno de considerar $^{38}$.

\section{5. Hacia la normalización}

A continuación se dará cuenta de algunas traducciones, ediciones y otros testimonios que apuntan a la normalización de la obra del autor entre el público lector.

Existen tres obras importantes en este proceso, cuya circulación se tiene constancia e información, aunque no ha sido posible localizarlos. El primero de ellos es una traducción francesa y el segundo, una antología dedicada a la literatura fantástica; y el tercero, una traducción al español.

Gracias a la información obtenida en un anuncio publicado en Le Trait d'Union, 23 de junio de 1872 (p. 3) se tiene noticia de que la Livrerie et papererie de L. Matty, ubicada en la calle de Cadena 24, puso a la venta un volumen de Contes de Hoffmann, por \$1.00. Las ediciones que responden a ese título son la traducción de Édouard Degeorge (Contes d'Hoffmann (faisant partie de ses dernières œuvres). Lyon: Doursy fils, 1848) y la traducción de Ancelot (Contes d'Hoffmann. París: Arnauld de Vresse, 1859). Existe otro anuncio, "Librería y papelería de L. Matty”, en El Siglo XIX, 9 de septiembre de 1872 (p. 4). Este es importante porque señala que se trata de una edición en doceavo, es decir, un libro cuyas medidas son aproximadamente 11 x $16 \mathrm{~cm}$. Ninguna edición francesa responde a esa descripción.

Uno de los acontecimientos más importantes para la literatura fantástica en México es la publicación de la antología "Novelas fantásticas en tres tomos". De acuerdo con el anuncio publicado en La Patria Ilustrada, 18 de febrero de 1884 (p. 110) en el primero de estos volúmenes presenta dos

\footnotetext{
${ }^{38}$ Aunque no tuvo la importancia la ópera, también es importante la puesta en escena del ballet Coppélia, con música de Léo Delibes, el 3 de agosto de 1904 en el Teatro Arbeu; que suscitó reacciones diversas y trajeron de nueva cuenta el interés del público por el personaje y su obra. La obra originalmente se estrenó en la Ópera de París (1870).
} 
cuentos de fuerte carga ominosa. "La iglesia de los jesuitas" ("Die Jesuiterkirche in G") y "La casa desierta" ("Das Öde Haus") pertenecientes a los Nocturnos (Nachtstücken, 1817) ${ }^{39}$. Aunque ha sido imposible localizar algún ejemplar y sólo se sabe de su contenido por los anuncios aparecidos en prensa, no sería aventurado suponer que las traducciones hayan sido hechas en México debido a que en esta edición también se encuentra "Las mil y segunda noches" de Edgar Allan Poe publicada por Ireneo Paz, cuento del bostoniano que primero fue traducido en edición mexicana antes que en francesa o española (Hernández Roura, 2016: 91-92).

Existe constancia de la circulación de una edición de El magnetizador por un anuncio de las novedades de las librerías de Andrés Botas y Miguel publicado en El País, 27 de noviembre de 1912 (p. 4). La obra no ha sido localizada, pero de acuerdo con él, se trató de un tomo en rústica que tuvo un costo de $\$ 0.50$.

Uno de los textos más célebres del autor, traducido en ese periodo es "Rat Krespel", perteneciente a Serapionsbrüder (1819-1821), cuento en el que todo ocurre dentro de una atmósfera onírica. "El consejero Crespel”, en El Diario del Hogar, 25 de enero de 1887 (p. 1-2 [Continúa el 26 pp. 2-3; el 28, pp. 2]). Las características del personaje que da título a la obra remiten a diversos desórdenes mentales: sus movimientos bruscos, sus arrebatos, su conversación que salta de un tema a otro y su carácter obsesivo lo presentan como un personaje caricaturesco, que sirve de contraste a la trágica acción que se narra: Un día llega el excéntrico personaje al pueblo de H... y se integra a la vida rural. El narrador interesado por él se percata de que hay un misterio en torno a Antonia, la hija del hombre, la obsesión Crespel por los violines y el canto prodigioso de la joven. Después de ser echado de la casa al intentar averiguar y de pasar tiempo fuera del lugar, regresa cuando la joven ya ha muerto. Descubre la causa: una falla orgánica y la equiparación entre la voz de ella y el sonido emitido por un violín.

Aunque existen traducciones que respetan el título de "Le Conseiller Krespel”, la división en capítulos o la traducción de términos geográficos permite ver que la obra no procede de las ediciones de Egmont (1840), de Ancelot (Contes d'Hoffmann, édition Arnauld de Vresse, 1859) o de la Bédollière (1862) y tampoco a la traducción de D.A.M., "El consejero Krespel”, contenido en Obras completas de E. T. A. Hoffmann. Cuentos fantásticos (Barcelona: Imp. de Llorens hermanos, 1847). Esto hace suponer que se trata de una obra traducida directo del alemán, sin embargo, el hecho de que se señalen las distancias en toesas, medida de longitud francesa que también se usó España a partir del régimen borbónico, y no en brazas (klafter), puede ser indicio de que procede de una traducción francesa no recogida en libro $^{40}$.

\footnotetext{
${ }^{39} \mathrm{El}$ mismo anuncio aparece el 10 de marzo (p. 158), 14 de abril (p. 238), 2 de junio (p. 350), 9 de junio (p. 366), 14 de julio (p. 446), 6 de octubre (p. 638), 13 de octubre (p. 654), 20 de octubre (p. 670), 27 de octubre (p. 686), 10 de noviembre (p. 718), 1 de diciembre (p. 766), 8 de diciembre (p. 782), 15 de diciembre (p. 798), 22 de diciembre (p. 814), 29 de diciembre (p. 830) de 1884 y 12 de enero (p. 30), 19 de enero (p. 46), 26 de enero (p. 62), 16 de febrero (p. 110) de 1885. ${ }^{40} \mathrm{Se}$ descarta como fuente de procedencia las obras francesas que llevan el título "Le Violon de Crémone" o "Le Chant d'Antonia", así como las españolas que traducen los mismos títulos.
} 
Los fragmentos de algunos textos críticos, artículos y notas de algunos escritores, afines o no a la estérica del autor insertos en artículos de diferente índole también son relevantes para el proceso descrito, como en el caso de Pedro Castera, quien señala en un artículo reivindicador de las mujeres

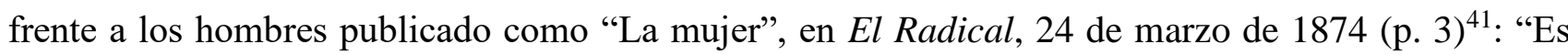
fantástico Hoffman [sic] pero lo es más Ana Radcliffe”. A este grupo de textos se suman, por ejemplo, los comentarios de Manuel de Olaguíbel, "Las rimas de Gustavo Adolfo Bécquer”, en El Artista, 1 de julio de 1874 (pp. 221-239). En ese artículo el autor reconoce el carácter fantástico de las obras del sevillano y lo compara con autores pertenecientes a este género que circulaban en ese momento: "bajo este punto de vista, debe Bécquer ser estudiado con todo detenimiento; mas para hacerlo es necesario ocuparse de sus cuentos fantásticos, que a mi juicio pueden competir con los mejores de Hoffman, de Erckmann-Chatrian y de Edgard Poé, y sólo un estudio de esta naturaleza puede formar un volumen" (p. 237) ${ }^{42}$. De no menor importancia es la posibilidad, de acuerdo con Sánchez Sánchez (2010: 15), de que el origen del seudónimo de Laura Méndez de Cuenca, "Stella", pudiera estar relacionado con Hoffmann, aunque de ser así, más bien correspondería al nombre de la amada del escritor en la ópera de Offenbach.

A la última década del siglo XIX pertenece un homenaje muy curioso que forma parte del poema "A Hidalgo" del escritor Andrés Ortega, publicado en Boletín Municipal. Órgano especial de la Asamblea de Concejales (Puebla), 22 de septiembre de 1893 (pp. 3-4). Aquí los versos: “¡Fantástica visión! Tú merecías / de Hoffman [sic] y de Píndaro divino, / en consorcio feliz, las armonías” (p. 4). El texto de Ortega muestra su admiración por el Padre de la Patria y en sus versos contiene dos motivos de asombro: por una parte, la aparición del escritor alemán y su vinculación con un autor pertenecientes a época y estilo tan lejanos; expresión en la que podría verse el afán de conciliación entre lo antiguo y lo moderno ${ }^{43}$.

El autor alemán aparece mencionado en Memorias de mis tiempos (1906). Guillermo Prieto se refiere a él en el tomo II, dedicado al periodo de 1840-1853 cuando relata lo que le aconteció durante su estancia en Zacatecas:

Las leyendas sobre los descubrimientos de las minas me entretenían como cuentos de Hoffman [sic]. Ya eran calaveras extraviadas en la montaña, que claman a Dios, y éste les manda pernoctar en tal punto, en que hacen lumbre, y la lumbrada deja entre sus cenizas una plancha de plata. Y en cuanto al carácter rumboso de los amos grandes, citaban el famoso bautismo en que desde la casa del padrino a la parroquia, se tapiza el suelo con andaderas de barras de plata. Ya por último, para dar a conocer el carácter soberbio y manirroto

${ }^{41}$ El texto comienza el 19 y termina el 25 de marzo.

${ }^{42}$ La figura de Gustavo Adolfo Bécquer es otra influencia de lo fantástico en México a considerar, ya que en sus obras asimiló tanto las aportaciones de Hoffmann como las de Edgar Allan Poe (Roas, 2002 y 2011). Sobre su recepción en México (Esteban, 2003: 36-46).

${ }^{43}$ Otra muestra de admiración forma parte de una de las entregas de la novela La dama de noche del escritor sevillano Manuel Fernández y González, en El Imparcial, 15 de marzo de 1899 (p. 1). La novela comenzó a publicarse en ese diario el 24 de febrero de 1899 (p. 3). En ella se observa el vínculo que se estableció con temas sobrenaturales, aunque siempre se le identifica en un lugar aparte: "Me acordé de todas las creaciones de la superstición. / De las almas en pena. / De los vampiros. / De los espectros. / De los wils. / De los duendes. / Recordé los cuentos de Hoffmann. / Los delirios de los poetas árabes. / Hasta los milagros consignados en los santos libros". 
del minero, se cuenta que un barretero fue a un cajón a comprar una tela rica para un regalo (Prieto, 1992: $331)$.

En este fragmento, Prieto manifiesta su afición a las obras de Hoffmann y las liga al placer que supone su lectura. Sobre este testimonio es necesario considerar también que Hoffmann es el autor de "Las minas de Falun” (“Die Bergwerke zu Falún”), cuento de ambiente minero que podría estar vinculado a este testimonio, más allá del placer y la fascinación que ejercieron sus historias en "Fidel".

El público identificaba el adjetivo "hoffmaniano" y a su creador con un estilo y una serie de temas. De eso aprovecha Ramón Correa en un texto publicado en La Patria, 18 de noviembre de 1909 (p. 6). "Un cuento de Hoffmann" está lejos de ser un texto apócrifo o una imitación, sin embargo, es una evidencia de que para ese momento los lectores estaban familiarizados con el alemán y permite dar cuenta del cambio de horizonte y de su normalización. Se narra la historia de un viejo solitario y avaro al que un miembro de su familia le sugiere que se deshaga de su fortuna y que reflexiones sobre el más allá. Al anciano, a quien la eternidad no le aterroriza, le asegura que la muerte le teme, al igual que toda la gente que lo rodea. Su interlocutor trata de convencerlo de que en el fondo su vida es triste y solitaria. El anciano le responde que nada de eso le importa, ni "la sociedad, ni la ley, ni Dios". El narrador asegura que el viejo irredento vive aún y que "la muerte no ha querido tocarle; el asco que produce lo sucio en demasía y la repugnancia propia para todo lo corrompido, lo escudan de morir" y que "aquel mal hombre con sus instintos de fiera va pasando por entre una multitud que le odia y le desprecia". Como se ha dicho, el público no estaba ante un cuento del alemán o que tuviera que ver directamente con el tipo de obras que cultivó, pero indudablemente Correa aprovechó la fama del alemán para referir un suceso que consideró de carácter increíble o absurdo.

Un fenómeno relacionado con el cambio de horizonte que tuvo lugar en la cultura mexicana se vincula estrechamente con el proceso de recepción de Edgar Allan Poe, que tuvo su inicio con la publicación de "Eleonora" en 1868 aunque pueden ubicarse las primeras menciones a él, hacia finales de la década anterior (Hernández Roura, 2016). La novedad del bostoniano con respecto al tratamiento de lo fantástico no desplazó a Hoffmann sino que atrajo la atención por su obra. Es particularmente ilustrativa de esta tendencia la declaración que forma parte de "Un triunfo sobre la muerte", en Alrededor del Mundo, 4 de junio de 1913, p. 9: “[El actor] Perier se caracteriza de la muerte y actúa en una historia sobre los cuentos de Hoffman, el Edgar Poe de Alemania”. Se trata de un testimonio de que la renovación de la literatura fantástica tuvo como consecuencia una revaloración de la tradición representada por Hoffmann.

Para terminar este recorrido es importante señalar que existe la constancia en la prensa mexicana de la circulación de otras obras de Hoffmann que formaron parte de este proceso, como por ejemplo 
"Don Juan"44, el "Consejero Crespel"45, "Aventuras en la noche de San Silvestre"46, "El dux y la dugaresa"47, "El hombre de arena"48, "Opiniones del gato Murr"49, "La iglesia de los jesuitas de G"50, y "El puchero de oro"51.

La reconstrucción de este fenómeno a través de las traducciones, artículos, notas y menciones periodísticas hace posible ver la compleja red de circulación que conformó la recepción de las traducciones del alemán. Un aspecto del fenómeno que salta a la vista es la preeminencia de las traducciones del francés, que se inserta dentro del proceso de traducción de la literatura alemana, junto con una doble mediatización, que pasa primero por Francia y luego por España. El proceso descrito muestra que se trató de una recepción fragmentaria y selectiva, que si bien podría llevar a suponer que la publicación de un número limitado de traducciones dificultaría que los lectores conocieran la obra del autor, se ve refutado por testimonios de la circulación de ediciones españolas y francesas que fueron determinantes para su difusión. Se observa el predominio de obras de carácter moral y no precisamente las más representativas del autor dentro de las traducciones revisadas; sin embargo, esto no constituyó un impedimento para que textos pertenecientes a Los Nocturnos, fueran conocidos. Como se puede observar, se privilegió la traducción de textos cortos, ideales para su publicación en diarios, y no hubo ediciones de Elixires del diablo (1815-1816), Gato Murr (1820-1822), La princesa Bambrilla (1821), Meister Floh (1922), novelas que tampoco aparecieron en España durante el periodo estudiado (Roas, 2002: 59), y que muy probablemente fueron conocidas gracias a las traducciones en francés; hecho que muestra la preeminencia de la consideración del autor como cuentista y no como novelista. Fue sobre todo en las tres últimas décadas del siglo XIX, coincidente con la publicación de obras de origen alemán, que cobró mayor celebridad y se le vinculó con otros cultivadores del mismo género. Al interés fundamental de autores como Dumas, Sand, Nodier, o incluso Scott, para su difusión, se sumarán Roa Bárcena, Altamirano, Gutiérrez Nájera, entre los mexicanos. Si bien podría resultar exagerada la idea

\footnotetext{
44 “Don Juan" pertenece al libro Phantasiestücke in Callots Manier (1814-1815). Apareció en español en la edición de las Obras completas por la imprenta Llorens traducidas por D.A.M. (1847). "El D. Juan de Mozart", en El Monitor Republicano [Secc. Variedades], 26 de diciembre de 1849 (p. 3).

45 Sobre "Rat Krespel": "El testimonio del difunto", en El Monitor Republicano, 20 de abril de 1862 (p. 3). [Primera publicación del folletín el 19 de abril 1862, p. 3]; "Mosaico", en México y sus costumbres, 24 de octubre de 1872 (pp. 6 7); Eusebio Martínez Velasco, “El zapatero de Nochebuena”, en La Convención Radical Obrera, 19 de abril de 1891 (p. 3).

46 Sobre "Las aventuras de la noche de San Silvestre" ("Die Abenteuer der Sylvester-Nacht”): “1884", El Tiempo, 31 de diciembre de 1884 (p. 3). El mismo texto apareció también como "1864”, en La Razón de México, 31 de diciembre de 1864 (p. 1); Luis Coloma S.J., “Qué sería?”, en El Tiempo, 25 de diciembre de 1887 (pp. 2-3).

${ }^{47}$ Sobre "Doge und Dogaresse", perteneciente a Serapionsbrüder (1819-1821): Proteo, "Crónica Musical. Otello", en El Siglo XIX, 25 de junio de 1871 (p. 1) [Se incluye una cita correspondiente a "El dux y la dugaresa", perteneciente a Los Nocturnos].

${ }^{48}$ Sobre "Der Sandmann": I.M. Altamirano, “El Salón en 1879-1880 (Impresiones de un aficionado)", en La Libertad, 16 de enero de 1880 (pp. 1-2); "Los títeres", en El Nacional, 3 de diciembre de 1891 (p. 2); M. Gutiérrez Nájera, "La política y los cuentos de hadas", en El Partido Liberal, 10 de febrero de 1892 (p. 1).

${ }^{49}$ Sobre Kater Murr: Serafín Ramírez, "Cartas. De artistas célebres", El Tiempo [Secc. Extranjero], 29 de enero de 1893 (p. 1).

${ }^{50}$ Sobre "Die Jesuiterkirche in G.": I.M. Altamirano, "La vida en México", en El Siglo XIX, 31 de marzo de 1894 (p. 1); Juan G. Iza, "Conversaciones semanarias”, en La Patria Ilustrada, 30 de julio de 1894 (pp. 362-364).

${ }^{51}$ Sobre "Der goldene Topf", perteneciente a Phantasiestücke in Callots Manier (1814-1815):"Limitations of Genious. Few Men Are Great in More Than One Direction”, The Mexican Herald, 1 de noviembre de 1903 (p. 10).
} 
de O de Bopp (1961: 123) de que era "el romántico alemán más conocido", no podemos dejar de observar que era bastante más célebre de lo que se podría suponer.

\section{Bibliografía}

ALTAMIRANO, Ignacio Manuel (1986): Obras completas III. Novelas y cuentos. Tomo I. México, SEP.

ALTAMIRANO, Ignacio Manuel (1988): Obras completas XII. Escritos de literatura y arte. Tomo I. México, SEP.

ALTAMIRANO, Ignacio Manuel (1989): Obras completas XIV. Escritos de literatura y arte. Tomo III. México, SEP.

BRAVO-VILLASANTE, Carmen (1992): El alucinante mundo de E. T. A. Hoffmann. Palma de Mallorca, J.J Olañeta.

BREUILLAC, Marcel (1906): «Hoffmann en France. Étude de littérature comparée», en Revue d'Histoire littéraire de la France, año 13, núm. 3, pp. 427-457.

BREUILLAC, Marcel (1907): «Hoffmann en France. Étude de littérature comparée (Suite)», en Revue d'Histoire littéraire de la France, año 14, núm. 1, pp. 74-105.

CASTEX, P.-G. (1951): Le conte fantastique en France. De Nodier à Maupassant. París, José Corti, 1962.

ESTEBAN, Ángel (2003): Bécquer en Martí y en otros poetas hispanoamericanos finiseculares. Madrid, Verbum.

GUTIÉRREZ DE VELASCO, Luzelena (2006): «El proyecto novelístico de Ignacio Manuel Altamirano», en Ignacio Manuel Altamirano. Para leer la Patria diamantina. Una antología general, ed. de Edith Negrín. México, Fondo de Cultura Económica, Fundación para las Letras Mexicanas, UNAM, pp. 365-379.

HERNÁNDEZ ROURA, Sergio Armando (2016): La recepción e influencia de Egar Allan Poe en México (1859-1922). Tesis de doctorado. Barcelona, Universidad Autónoma de Barcelona.

HOFFMAN, E. T. A. (2006): Cuentos de Hoffmann. Trad. y prólogo de José María Roa Bárcena. México, Factoría Ediciones.

JAUSS, H. R. (2000): La historia de la literatura como provocación. Barcelona, Península.

MARTÍNEZ DE CASTRO, Luis (2003): La visita inesperada. Ed. y estudio introductorio de Marco A. Campos. México, UNAM.

MARTÍNEZ, José María (2011): «Introducción», en Cuentos fantásticos del romanticismo hispanoamericano. Madrid, Cátedra.

O. DE BOPP, Marianne (1961): Contribución al estudio de las letras alemanas en México. México, UNAM. 
PÉREZ GIL, Violeta (1993): «La recepción de E. T. A. Hoffmann. Primeras traducciones al francés y al español», en Margit Raders y Julia Sevilla (eds.), III Encuentros Complutenses en torno a la traducción: 2-6 de abril de 1990. Madrid, Editorial Complutense, pp. 225-232.

PRIETO, Guillermo (1992): Obras completas I. Memorias de mis tiempos. Presentación y notas de Boris Rosen Jélomer. Prólogo de Fernando Curiel. México, Conaculta.

ROAS, David (2002): Hoffman en España. Recepción e influencias. Madrid, Biblioteca Nueva.

ROAS, David (2011): La sombra del cuervo. Edgar Allan Poe y la literatura fantástica del siglo XIX. Madrid, Devenir.

RODRÍGUEZ GUTIÉRREZ, Borja (2004): Historia del cuento español (1764-1850). Madrid; Frankfurt, Iberoamericana Vervuert.

ROSADO, Juan Antonio (2015), «Altamirano y E. T. A. Hoffmann», en Siempre, núm. 3237, XLII, 28 de junio, pp. 80-81.

RUKSER, Udo (1977): Goethe en el mundo hispánico. México, Fondo de Cultura Económica.

SAFRANSKI, Rüdiger (2009): Romanticismo. Una odisea del espíritu alemán. Barcelona, Tusquets. SÁNCHEZ SÁNCHEZ, Roberto (2010): «Advertencia editorial», en Laura Méndez de Cuenca, Simplezas y otros cuentos. México, UNAM, pp. 11-18.

SAND, George (1865): Théâtre de Nohat. París, Lévy Frères.

SPOELBERCH DE LOVENJOU, Ch. de (1968): Histoire des Euvres de Théophile Gautier. Ginebra, Slatkine Reprints.

STAPLES, Anne (1997), «La lectura y los lectores en los primeros años de vida independiente», en Historia de la lectura en México. México, Colegio de México, 2005, pp. 94-126.

STISTRUP-JENSEN, Merete (2011): «'Un pastiche d'Hoffmann et de moi': Sand aux frontièresdes genres», en Nigel Harkness y Jacinta Wright (eds.), George Sand: Intertextualité et Polyphonie I. Palimpsestes, Échanges, Réécritures. Berna, Peter Lang, pp, 225-238.

TEICHMANN, E. (1961): La fortune d'Hoffmann en France. París, Genf. 